\title{
A study on the use of existing pump as turbine
}

\author{
Md Rakibuzzaman ${ }^{1}$, Keum-Young Jung ${ }^{2}$, and Sang-Ho Suh ${ }^{2,3, *}$ \\ ${ }^{1}$ Future Technology \& Photography Institute, Gyeonggi-Do, 14051, Korea \\ ${ }^{2}$ KSB Korea Ltd., 13, Hannam-daero 20-gil, Yongsan-gu, Seoul, 04419, Korea \\ ${ }^{3}$ Department of Mechanical Engineering, Soongsil University, Seoul, 06978, Korea
}

\begin{abstract}
Cavitation is an abnormal physical phenomenon which occurs in relatively low-pressure regions in turbomachinery such as pumps and hydraulic turbines. A comparison between the pump and turbine cavitation behavior is a significant and essential process. The work investigates feasibility of turbine using existing pump and a comparative study of the cavitation characteristics on a centrifugal pump as turbine numerically and experimentally. The current work adopted the Rayleigh-Plesset cavitation model as the source term for inter-phase mass transfer to predict cavitation characteristics. The experimental data were compared with the numerical results and were found to be in good agreement. Results of the comparative study showed that cavitation first occurred at the suction leading edge on the impeller blades and attached cavitation observed on the impeller blade at the lower suction head in pump mode; however, for the turbine mode, the development of vortex cavitation happened at the runner outlet near the trailing edge on the impeller blades. Also, in the pump, the cavitation became larger from shroud to the hub and the cavitation rapidly extended from the suction side to the pressure side. On the other hand in the turbine mode, as the cavitation number decreased more vapor bubbles are drawn up at the runner outlet near trailing edge on the blade suction side.
\end{abstract}

\section{INTRODUCTION}

Pumps are employed to improve the pressure of the fluid by consuming external energy or mechanical energy. And a centrifugal pump can be operated in reverse direction as a renewable energy generator in microhydro-power plants or as a power recovery turbine in the process industry [1-3]. Pump as turbine (PAT), is one kind of low-cost, affordable and attractive alternatives for mini/micro hydropower plants. In principle, it is just the pump run in turbine mode by rotating it in reverse direction [4-6]. The basic hydraulic behavior of pumps operating as hydraulic power recovery turbines is not much different from that of a pump, following the same sort of affinity laws over narrow ranges. Generally, the Francis turbine efficiency is more than $90 \%$, but when considering flow from low reservoir to high reservoir the Francis turbine is not suitable and in this case, the pumpturbine is used. Tan et al. [7] presented a comprehensive correlation aimed to obtain the accurate prediction of the turbine model operations of centrifugal pumps and used experimental data of various pumps representing the centrifugal pump configurations in terms of specific speed. Fecarotta et al. [8] presented the reliability of the affinity law to predict the behavior of a PAT under various speeds and found a significant difference between the theoretical model and the experimental results. Barbarelli et al. [9] introduced a predictive model to estimate the performance of centrifugal pumps used as turbines and obtained that the estimation error is small and acceptable for this kind of application. Doshi et al. [10] experimentally investigated the relative effects of blade and shroud rounding for the inlet impeller round in PAT.

On the other hand cavitation is well recognized as a common physical phenomenon that may cause turbomachines (pumps, turbines, etc.) malfunctioning due to improper design. It is the process of the formation of vapor bubbles which can be generated in relatively low-pressure regions within a flow in radial flow pumps [11]. Cavitation is a primary cause of a significant reduction in performance, as noticed by reduced mass flow rates, noise, vibrations, and erosion in radial flow pumps [12]. It has been found that cavitation erosion is mainly related to the length of the attached sheet cavity, with the temperature of the liquid being pumped affected by vapor pressure, as well as circumferential speed and the properties of the impeller material [13]. Additionally, for low cavitation numbers, hydraulic efficiency, flow coefficient, and the head coefficient can be decreased. Rakibuzzaman investigated cavitation phenomena with variable speeds by thermodynamic effects through numerically $[14,15]$ (Rakibuzzaman et al., 2016, 2017). CFD is being applied in the design of radial flow pumps and turbines which can be employed for the numerical simulation to obtain the hydraulic performances. CFD has proven to be a handy tool in the investigation of the flow of pumps and turbines, both in design and

\footnotetext{
* Corresponding author: $\underline{\text { suhsh@ssu.ac.kr }}$
} 
performance prediction. Recently an experimental and numerical simulation studied on performance characteristics for the variable speed drive system of a multistage centrifugal pump [16]. Bakir et al. [17] coupled the Rayleigh-Plesset equation to the flow solver and computed void fraction in the pump inducer. The cavitation analysis performed in centrifugal pumps using multiphase CFD and pointed out the head inception and breakdown point [18]. The different NPSH characteristics studied in a centrifugal pump [19]. Rakibuzzaman et al. [20] studied on cavitating flow analysis and a relationship between cavitation incipient and net positive suction head characteristics for the inverter drive multistage centrifugal pump. He also studied on cavitation characteristics in a multistage centrifugal pump though experimentally and numerically [21].

The prediction of cavitating flow is always a particular interest in the application of hydraulic turbine which shows the decrease performance of the operation as they get damaged due to cavitation, silt erosion, material defects and fatigue [22]. Thus, to find out a suitable way to predict cavitation phenomenon, especially the critical cavitation number and the cavitation location, has been an interesting topic in the field of hydraulic machinery. Avellan (2004) presented a study of different cavitation phenomena based on a literature survey in hydraulic machinery [23]. Maekawa et al. [24] (2003) studied on cavitation erosion in Francis turbines through acceleration tests and a relationship between the intensity of cavitation, and the progression of erosion was established. Kumar and Saini (2010) conducted a study of different causes of hydro-turbines and the proper corrective actions based on a literature survey of several features associated with cavitation [25]. A comparison between the pump and turbine cavitation behaviors is also a significant and essential process.

The current works are focused on investigating the feasibility of turbine using existing pump and cavitation characteristics in the centrifugal pump as turbine numerically and experimentally. The Rayleigh-Plesset cavitation model was accounted for cavitation prediction. The development of cavitation was also described according to cavitation number in the head drop lines.

\section{Numerical Method}

The 3D geometry of the horizontal single suction volutetype centrifugal pump was selected to analyse the characteristics of the PAT as shown in Fig. 1. Table 1 shows the specification of the centrifugal model pump for simulations. The schematic flow diagram of pump as turbine is represented in Fig. 2. The model pump was meshed by ANSYS ICEM-CFX (Ansys Inc. 2015, USA) based on finite volume methods (FVM) [26]. For noncavitating conditions, the total meshing grids were $1,975,956$ and 622,493 . The unconstructed tetra-prim meshing of the centrifugal pump is shown in Fig. 3. In order to reduce the influence of the grid number on the computational results, a grid dependency study at the design point $\left(450 \mathrm{~m}^{3} / \mathrm{hr}\right)$ under non-cavitation condition was carried out a steady state and it was found that the head deviation was less than $1 \%$ as shown in Fig. 4 [2728].

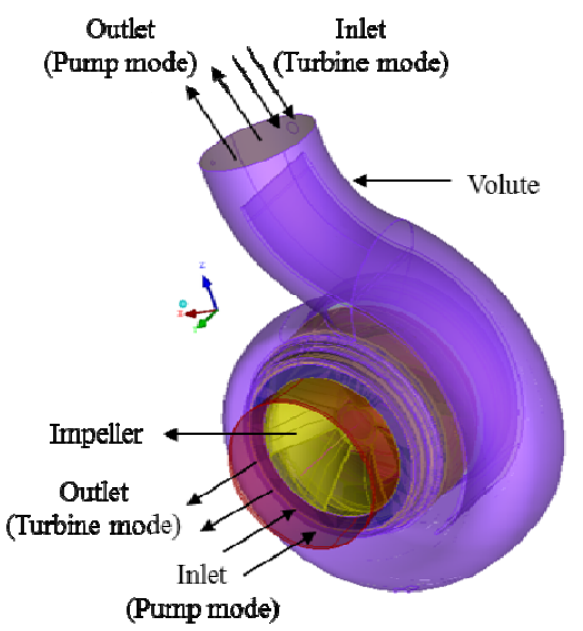

Fig. 1. Pump-turbine model.

Table 1. Pump impeller design specification.

\begin{tabular}{|c|c|c|c|c|}
\hline $\begin{array}{c}\text { Design } \\
\text { flow } \\
\mathrm{Q} \\
{\left[\mathrm{m}^{3} / \mathrm{hr}\right]}\end{array}$ & $\begin{array}{c}\text { Rotation } \\
\text { speed } \\
\mathrm{N} \\
{[\mathrm{rev} / \mathrm{min}]}\end{array}$ & $\begin{array}{c}\text { Blade } \\
\text { number } \\
\mathrm{Z}\end{array}$ & $\begin{array}{c}\text { Impeller } \\
\text { diameter } \\
\mathrm{D}_{2} \\
{[\mathrm{~m}]}\end{array}$ & $\begin{array}{c}\text { Impeller } \\
\text { eye } \\
\text { diameter } \\
\mathrm{D}_{1} \\
{[\mathrm{~m}]}\end{array}$ \\
\hline 450 & 1750 & 6 & 0.262 & 0.188 \\
\hline
\end{tabular}

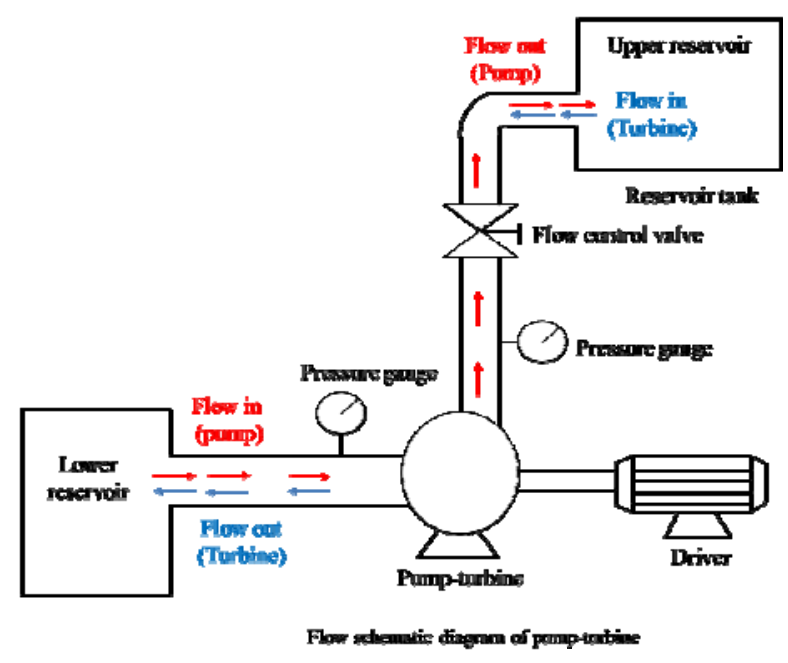

Fig. 2. Flow schematic of the centrifugal pump-turbine.

The 3-D flow solution of the RANS (ReynoldsAveraged Navier-Stokes) equations for turbulent flows were adopted in CFD [26]. Under the non-cavitation condition, the impeller domain was rotating on y-axis at $1,750 \mathrm{rpm}$ with different flow operating conditions, and the suction pipe and volute were on a stationary domain. 
A frozen rotor was applied to couple the rotation and stationary domain.

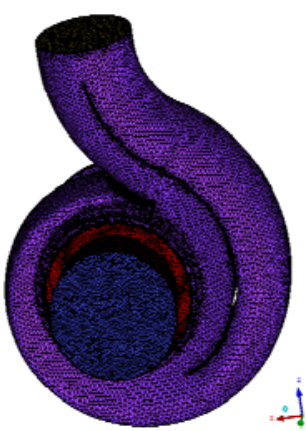

Volute chamber

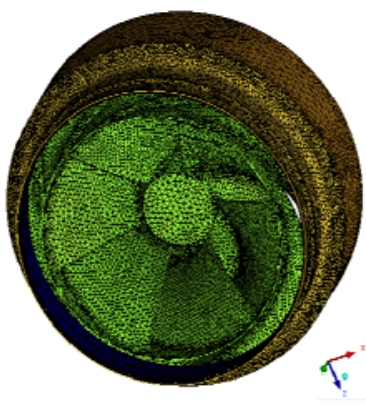

Impeller
Fig. 3. Unstructured prism grids of centrifugal pump.

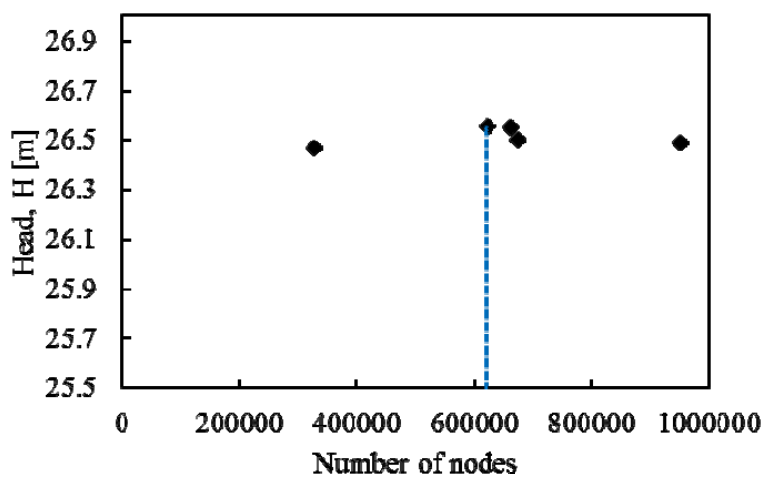

Fig. 4. Grid independence test of the centrifugal pump.

The impeller-volute of the pump domain is shown in Fig. 5. The boundary conditions were set as follows: mass flow rate - inlet boundary at the pump inlet (the suction pipe) and pressure - outlet boundary at the pump outlet for the pump mode. Pressure - inlet boundary at the turbine inlet (the pump outlet) and the mass flow rate was imposed at the outlet boundary for the turbine mode. All boundary walls were assumed as smooth walls with non-slip conditions. The SST turbulence model [29-31] was used to solve the turbulence phenomena of the fluid. High resolution for the advection scheme, the first order for the turbulence numeric and SIMPLEC algorithms were considered in the solver control. The residual value was $1 \times 10-5$ controlled by convergence criteria.

For cavitation analysis, the flow conditions were considered a steady state, incompressible, homogeneous two-phase flow (water and vapor). The pressure was set as the boundary condition at the inlet at the pump inlet and mass flow rate at the pump outlet for pump mode. For turbine mode, the mass flow rate was set as the boundary condition at the turbine inlet and pressure at the turbine outlet. The steady non-cavitation result was prepared as the initial value for the homogeneous twophase flow simulation for the numerical stability. The water temperature was set as standard temperature and pressure (STP) during the simulation. The saturated vapor pressure was set $3169 \mathrm{~Pa}$. The Reynolds-averaged
Navier-Stokes (RANS) equations with the SST turbulence model were discretized by the FVM and Rayleigh-Plesset cavitation model was adopted. Advection term dealt with high-resolution discretization scheme. The residual for velocity and pressure was set to $1 \times 10^{-5}$ as convergence criteria.

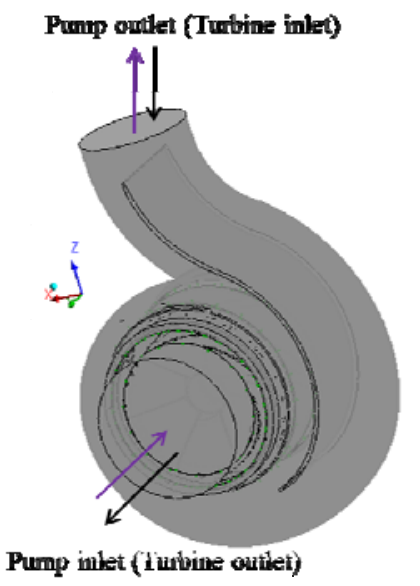

Fig. 5. Fluid domain of the pump-turbine for computer simulation.

\section{Results and Discussion}

\subsection{Validation of numerical performances}

To confirm the numerical results, simulation results were validated with experimental data. Fig. 6 shows the experimental and computational results at different operating conditions at pump mode. As shown, a good agreement between the two results was obtained at given flow rates. In this comparison, the average deviation of the head values was only $3.01 \%$, the highest deviation of $12.67 \%$ for the highest flow rate at $1750 \mathrm{rpm}$. The pump efficiency shows an average deviation was only $3.63 \%$ and the highest deviation was $8.53 \%$ for the highest flow rate of $559.68 \mathrm{~m}^{3} / \mathrm{hr}$. Also, for the pump shaft power, the average deviation was only $4.74 \%$. The average head of the experimental and numerical simulations had only $3.01 \%$, as was expected. Fig. 7 shows the computational results in turbine mode. It is seen from that figure that there is a similar trend between the simulation results and the experiment for the hydraulic performance curves [32].

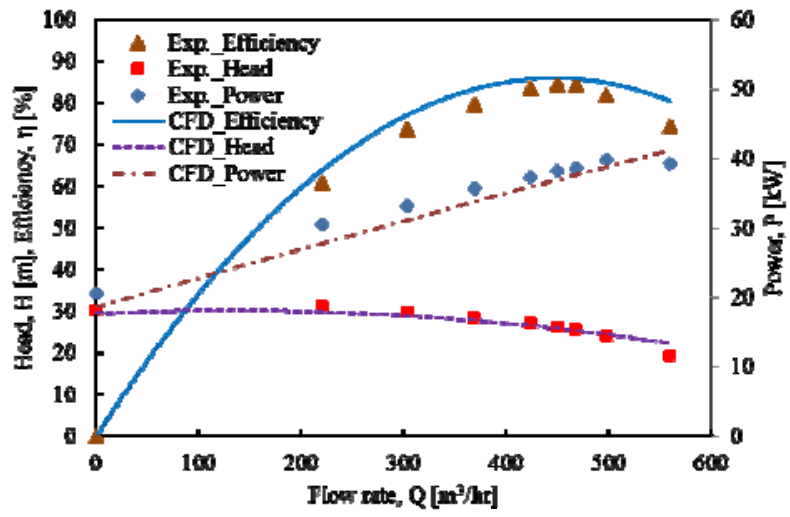


Fig. 6. Experimental and computational performances at pump mode.

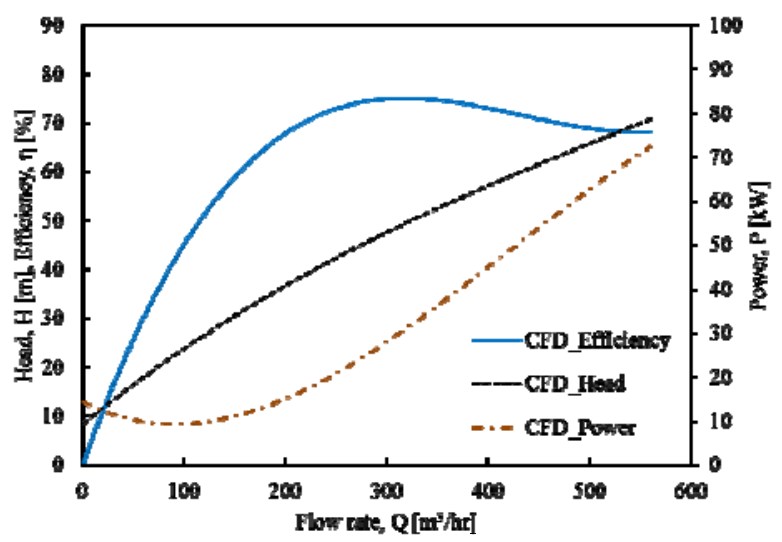

Fig. 7. Computational performances at turbine mode.

Table 2. Hydraulic Performance at BEP in pump and turbine modes.

\begin{tabular}{|c|c|c|c|c|}
\hline Mode & $\begin{array}{c}\mathrm{Q} \\
{[\mathrm{m} 3 / \mathrm{hr}]}\end{array}$ & $\begin{array}{c}\mathrm{H} \\
{[\mathrm{m}]}\end{array}$ & $\begin{array}{c}\mathrm{P} \\
{[\mathrm{kW}]}\end{array}$ & $\begin{array}{c}\eta \\
{[\%]}\end{array}$ \\
\hline Pump & 450 & 26.55 & 36.47 & 85.67 \\
\hline Turbine & 368.64 & 54.11 & 41.76 & 76.90 \\
\hline
\end{tabular}

\subsection{Performance characteristics}

As shown in Figs. 6 and 7, the pump head decreases with the increasing flow but the head consumed by the turbine increases with increasing flow rate. The former magnitude of the slope is larger than the latter. The shaft power of pump and turbine increases with increasing flow rate. The slope of the turbine shaft power is greater than the pump. As can be seen from these figures that the efficiency was $85.67 \%$ at the rated flow rate of 450 $\mathrm{m}^{3} / \mathrm{hr}$ at pump mode but in the turbine mode, the flow rate of $368.64 \mathrm{~m}^{3} / \mathrm{hr}$ the maximum efficiency was $76.90 \%$. The efficiency difference was only $9.96 \%$. The power output was $37.47 \mathrm{~kW}$ at pump mode and power output was only $41.76 \mathrm{~kW}$ at turbine mode. In this case, the power increased up to $4.3 \%$ than pump mode. Table 2 illustrates the hydraulic performances at the best efficiency point (BEP) both in pump and turbine modes. When the flow is in a range before best efficiency point (BEP), the hydraulic efficiency of turbine declines sharply compared with the pump efficiency. However, it shows a wider high-efficiency zone with slight declination when the flow rate is above BEP. The turbine should be operated in a higher flow rate due to being the load for a certain small flow rate.

On the other hand, the velocity contours were observed in the flow field of the PAT mode as shown in Fig. 8 at a flow rate of $450 \mathrm{~m}^{3} / \mathrm{hr}$. The velocity was smoothly distributed at the pump mode and high velocity occurred at the volute chamber near the corner. But in the turbine mode, the velocity unsmoothly distributed. The velocity was low at the leading edge of the impeller and flows were separated due to the wake of formation. This phenomena occurs because of the relative velocity drop at the impeller inlet (turbine mode) resulted from the recirculation zone. The velocity was highest at the outlet side near the hub of the trailing edge of the impeller vane. Also, on the outlet side of the impeller, a vortex was formed centrally at the outlet of the pipe. The resulted recirculation area causes the decrease in efficiency at turbine mode.
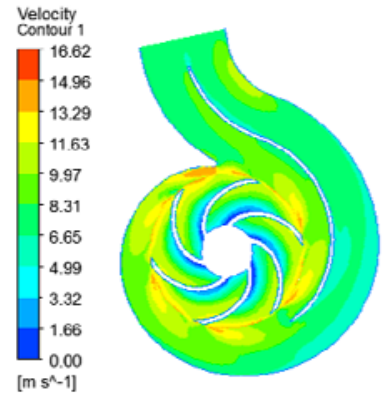

(a) Pump (450 $\left.\mathrm{m}^{3} / \mathrm{hr}\right)$

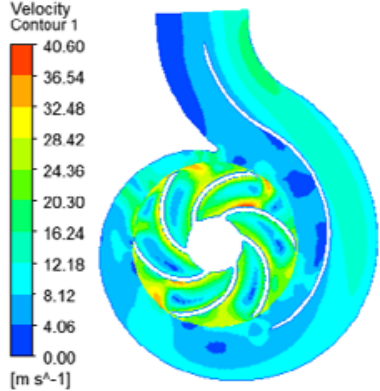

(b) Turbine $\left(450 \mathrm{~m}^{3} / \mathrm{hr}\right)$
Fig. 8. Velocity contours of (a) pump and (b) turbine mode at flow rate of $450 \mathrm{~m}^{3} / \mathrm{hr}$.

\subsection{Cavitation effects in pump and turbine}

In this study, numerical simulation has been performed in the rated operating range both in pump and turbine modes. Fig. 9 shows the computed values of the total head versus cavitation number $(\sigma)$ at rated flow operating conditions (Qd.p.) of the pump mode. In this figure, Qd.p. is the flow rate at the design point. The head drop line was obtained by gradually reducing the suction pressure. The initial decrease of the cavitation had no effect on the head drop line because of the pump and the total head remained unchanged. When cavitation number decreases, total head decrease and drops sharply at lower $\sigma$. This head drop varies for different flow rates. When the flow rates are larger than Qd.p. (Q>Qd.p.) heads are smaller than that of Qd.p. and when flow rates are smaller than the Qd.p. $(\mathrm{Q}<\mathrm{Qd} . \mathrm{p}$.), heads are larger than that of it. From these results, 3\% head drop accounted for cavitation conditions. It is seen from the literature, that the predicted head drop shows a similar trend with experimental results [21].

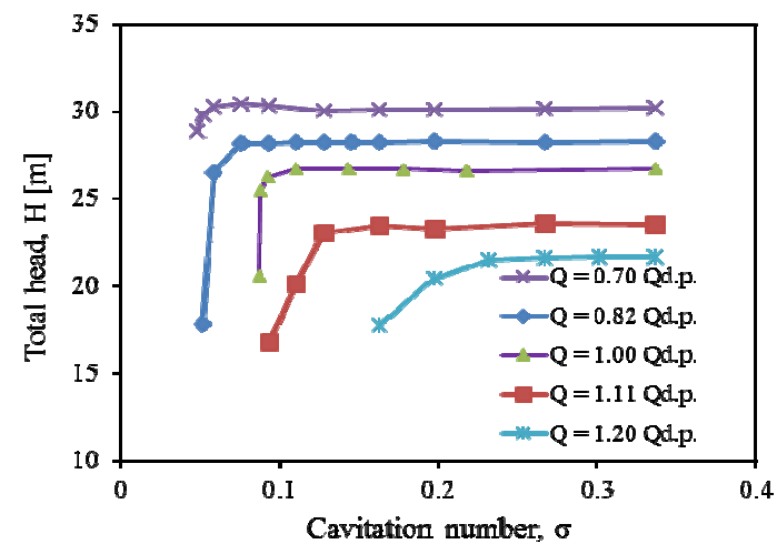


Fig. 9. Computed head drop line at rated flow rate at pump mode.

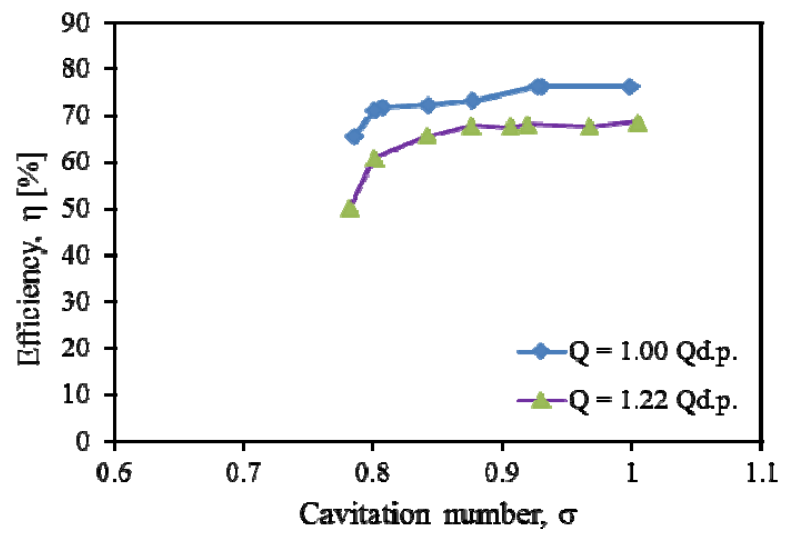

Fig. 10. Computed head drop line at rated flow rate at turbine mode.

At turbine mode, the cavitation effects are similar with those of the pump mode as shown in Fig. 10. The curves show that at some limiting cavitation number the curve performance becomes nearly vertical and the drops becomes severe at the breakdown point. The volume fraction of vapor is an important parameter for predicting cavitating flow both in pump and turbine modes. The quantity of the liquid-vapor mixture is a faction varies between 0 and 1 , with a value of 1 indicating $100 \%$ of vapor bubbles. Fig. 11 shows cavity volume fraction variation with different $\sigma$, i.e $0.178,0.143,0.11$ and 0.092 at the design flow rate $450 \mathrm{~m}^{3} / \mathrm{hr}$ at pump mode. The volume contours show 0 to 0.915 . From this figure, the cavitation occurrences were observed in the developed pump impeller. The cavitation bubbles grew and appeared at first on the suction zone near the blade leading edge. The pressure in this section was smaller than the shroud due to the centrifugal force of the pump impeller. So, the cavitation became larger from hub to the shroud side. The cavitation also rapidly grew on the pressure side. When the $\sigma$ value decreases, the cavitation region increased from leading suction edge to trailing edge, which was a significant factor on the impeller blades. For $\sigma=0.110$, at that point, the pump head began to drop. In this case, the pressure loading was increased on the impeller blade. For $\sigma=0.092$ the cavitation length was almost fully formed on the blade impeller and the length of bubble cavities increased from the leading edge to the trailing edge. At this stage, the flow pathway was almost obstructed by the cavities, which might have formed a pitting on the blade, which could block the internal flow of the pump geometry. In this case, the influence of the cavitation on the pressure loading distribution of the pressure would be reduced both at the leading and trailing edge.

Also, cavitation performances were investigated in the turbine mode at a flow rate of $368.64 \mathrm{~m}^{3} / \mathrm{hr}$. Figure 12 shows the volume fraction of water vapor distribution on the runner blades at four different Thoma cavitation number $(\sigma=0.876, \sigma=0.843, \sigma=0.801$, and $\sigma=0.782)$ at rated condition. It is seen from the figures that as the cavitation number decreased more vapor bubbles are generated near the leading edge on the blade suction side. Vortex cavitation occurred on the impeller hub centrally in turbine mode. This type of cavitation is quite sensitive to the content of cavitation nuclei and to the value of Thoma number.

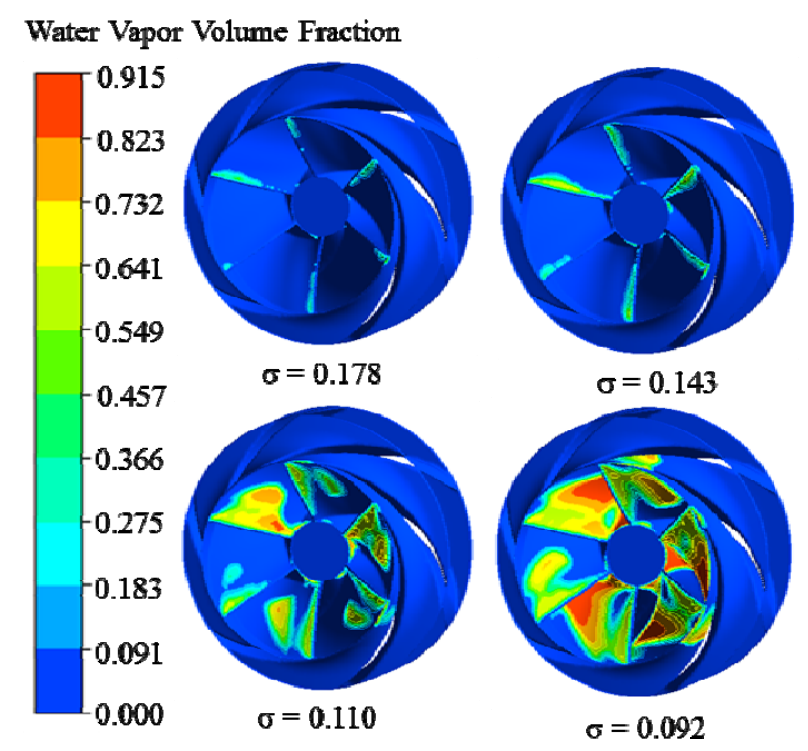

Fig. 11. Cavitation phenomena in the pump impeller at flow rate of $450 \mathrm{~m}^{3} / \mathrm{hr}$.

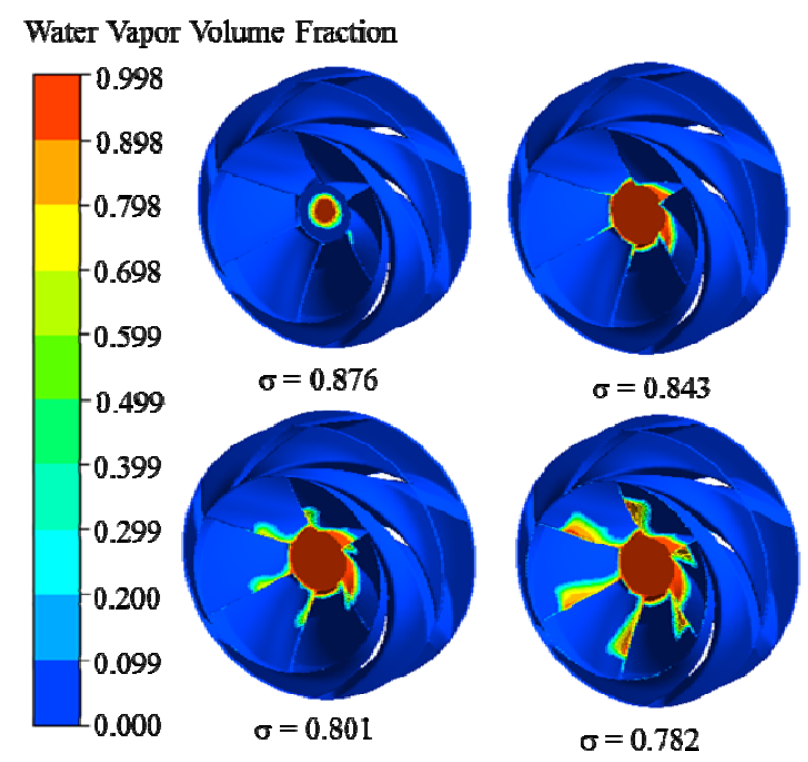

Fig. 12. Cavitation phenomena on the impeller blade at flow rate of $368.64 \mathrm{~m}^{3} / \mathrm{hr}$ at turbine mode.

\subsubsection{Comparison of pump and turbine cavitation}

In comparison, in the pump mode, the cavitation first occurred at the suction leading edge on the impeller blades and attached cavitation observed on the impeller blade at the lower suction head; however for the turbine mode, the development of vortex cavitation happened at the impeller hub centrally and outlet near the trailing edge on the impeller blades. Also, in the pump, the 
cavitation became larger from shroud to the hub and the cavitation rapidly extended from the suction side to the pressure side. On the other hand in the turbine mode, as the cavitation number decreased more vapor bubbles are drawn up at the hub and the impeller outlet near trailing edge on the blade suction side.

\section{Conclusions}

The main topic of this study was to investigate the feasibility of turbine and cavitation characteristics of existing centrifugal pump. In all cases, a perfect initial centrifugal pump without any changes of the geometry was investigated. In the real-world case, cavitation may trigger an increase in impact; in the pump model, the computed performance was compared with experimental data at different operating conditions and a good agreement occurred between them. At pump mode, at rated flow rate of $450 \mathrm{~m}^{3} / \mathrm{hr}$ the maximum efficiency was $85.67 \%$. But in the turbine mode, the maximum efficiency was $76.90 \%$ at the flow rate of $368.64 \mathrm{~m}^{3} / \mathrm{hr}$. The power output was $37.47 \mathrm{~kW}$ at pump mode but power output was only $41.76 \mathrm{~kW}$ at turbine mode. The use of exiting pump as turbine is applicable. The turbine mode efficiency of $77 \%$ was relatively lower than the pump efficiency of $85 \%$. Nevertheless, the turbine efficiency is not bad to use as turbine. When turbine mode adopted, cavitation performances was estimated and described according to different $\sigma$. Results of the current work show that the vortex cavitation can directly lead to losses in efficiency. On top of this, in cavitation, this study notes that the cavitation abrasion propagation started mainly from the leading edge suction side to the trailing edge pressure side of the impeller at pump mode. But in turbine mode, cavitation propagation mainly started from the center of the impeller and distributed to the trailing-edge at suction side. Therefore, without significant design and manufacturing of the new turbine, it can be used as turbine of manufactured pump.

\section{Acknowledgements}

The research was supported by the Namyang Energy and Engineering and KSB Korea for the promotion of science.

\section{References}

1. D. Y. Li, H. J. Wang, Y. L. Qin, et al., Mechanism of high amplitude low frequency fluctuations in a pump-turbine in pump mode, Renewable Energy 126, 668-680 (2018).

2. S. Jain, and R. Patel, Investigations on pump running in turbine mode: A review of the state-ofthe-art, Renewable and Sustainable Energy Reviews 30(2), 841-868 (2014).

3. X. L. Fu, D. Y. Li, H. J. Wang, et al. Energy Analysis in a Pump-Turbine during the Load Rejection Process, ASME J. Fluids Engineering 140(10), 101107 (2018).
4. A. Williams, Pumps as turbines. A user's guide, Intermediate Technology Publications, London, 1995.

5. S. S. Yang, F. Y. Kong, W. M. Jiang, et al. Research on impeller trimming to the influence of pump as turbine, Computer and Fluids 67(8), 72-78 (2012).

6. T. Lydon, P. Coughlan, and A. McNabola, Pressure management and energy recovery in water distribution networks: Development of design and selection methodologies using three pump-asturbine case studies, Renewable Energy 114, 10381050 (2017).

7. X. Tan, and A. Engeda, Performance of centrifugal pumps running in reverse as turbine: Part IIsystematic specific speed and specific diameter based performance prediction, Renew Energy 99, 188-197 (2016).

8. O. Fecarotta, A. Carravetta, H. M. Ramos, et al. An improved affinity model to enhance variable operating strategy for pumps used as turbines, J. Hydraul Res., 3, 1-10 (2016).

9. S. Barbarelli, M. Amelio, and G. Florio, Predictive model estimating the performances of centrifugal pumps used as turbines, Energy 107, 103-121 (2016).

10. A. Doshi, S. Channiwala, and P. Singh, Inlet impeller rounding in pumps as turbines: An experimental study to investigate the relative effects of blade and shroud rounding, Exp Therm Fluid Sci. 82, 333-348 (2017).

11. B. Schiavello, and F. C. Viser, Pump cavitationvarious NPSHR criteria, NPSHA margins, and impeller expectancy, Proceedings of the twenty fifth international pump users symposium, pp. 113-144 (2009).

12. T. Asahara, Pumping Station Engineering Hand Book, Japan Association of Agriculture Engineering Enterprises, Tokyo, Japan, 1991.

13. C. E. Brennen, Hydrodynamics of pump, Oxford University Press, Oxford, UK, 1994.

14. M. Rakibuzzaman, K. Kim, and S. -H. Suh, Numerical Analysis of Cavitation phenomena with Variable Speed Centrifugal Pump, J. Power Technologies 96(4), 306-311 (2016).

15. M. Rakibuzzaman, N. Park, and S. -H. Suh, Analysis of Cavitation with Rotational Speed and Water Temperature Changes of Centrifugal Pump, KSFM J. of Fluid Machinery 20(5), 40-45, (2017).

16. M. Rakibuzzaman, S.-H., Suh, K. Kim, et al. A study on multistage centrifugal pump performance characteristics for variable speed drive system, Procedia Engineering 105, 270-275 (2015).

17. F. Bakir, R. Rey, A. G. Gerber, T. Belamri, and B. Hutchinson, Numerical and Experimental Investigations of the Cavitating Behavior of an Inducer, Int. J. Rotating Machinery 10, 15-25 (2004). 
18. R. B. Medvitz, R. F. Kunz, et al. Performance analysis of cavitating flow in centrifugal pumps using multiphase CFD, J. of Fluids Engineering 124, 377-383 (2002).

19. S. Bruno, and C. V. Frank, Pump cavitation-various NPSHR criteria, NPSHA margins, and impeller expectancy, Proceedings of the twenty fifth international pump user's symposium, 113-144, (2009).

20. M. Rakibuzzaman, S. -H. Suh, and H. - H. Kim, Relationship between cavitation incipient and NPSH for inverter drive centrifugal pumps, KSFM J. of Fluid Machinery 18(6), 76-80 (2015).

21. Rakibuzzaman, M., Kim, K., and Suh, S.-H, Numerical and experimental investigation of cavitation flows in a multistage centrifugal pump, J. Mechanical Science and Technology, 32(3), 10711078 (2018).

22. S. Liu, Numerical simulation of 3D cavitating turbulent flow in Francis turbine, Proceedings of FEDSM2005, Houston, TX, USA, June 19-23, 2005.

23. F. Avellan, Introduction to cavitation in hydraulic machinery, The 6th Int. Conference on Hydraulic Machinery and Hydrodynamics Timisoara, Romania, October 21 - 22, 11-22, 2004.

24. M. Maekawa, K. Miyagawa, T. Komuro, and H. Fukuda, Study of cavitation erosion on hydraulic turbine runners, 5th Int. Symp. on Cavitation (CAV2003), Osaka, Japan, November 1-4, 2003.

25. P. Kumar, and R. P. Saini, Study of cavitation in hydro turbines-a review, Renewable and Sustainable Energy Reviews 14(1), 374-383, (2010).

26. Ansys Inc. 2013, ANSYS-CFX (CFX Introduction, CFX Reference guide, CFX Tutorials, CFX-Pre User's Guide, CFX-Solver Manager User's Guide, Theory Guide), release 15.00, USA.

27. H.-H. Kim, M. Rakibuzzaman, K. Kim, S. -H, Suh, Flow and Fast Fourier Transform Analyses for Tip Clearance Effect in an Operating Kaplan Turbine, Energies 12, 264 (2019).

28. M. Rakibuzzaman, H.-H. Kim, K. Kim, S.-H. Suh, K. Y. Kim, Numerical Study of Sediment Erosion Analysis in Francis Turbine, Sustainability 11, 1423 (2019).

29. D. C. Wilcox, Turbulence Modeling for CFD, 1st edition, DCW Industries, Inc., California, USA, 1994.

30. F. R. Menter, Two-Equation Eddy-Viscosity Turbulence Models for Engineering Applications, AIAA Journal 32(8), 1598-1605 (1994).

31. N. J. Georgiadis, D. A. Yoder, and W. B. Engblorn, Evaluation of modified two-equation turbulence models for jet flow predictions, AIAA Journal 44(12) 3107-3114 (2006).

32. D. Liang, D. Cui, L. Hai, and F. Zhao, A hydraulic performance comparison of centrifugal pump operating in pump and turbine mode, J. Thermal Science JTS-19-0121 (2019). 